\title{
Haemophagocytic Syndrome in a Four Year Old Male Child with Plasmodium Vivax Infection
}

\section{Bhatia $\mathbf{R}^{1}$, Bhatia $\mathbf{G}^{2}$}

${ }^{1}$ Dr Ravi Bhatia, MBBS, DNB Pediatrics, Assistant Professor, Department ofPaediatrics, Pacific Medical College and Hospital, Udaipur,Rajasthan, India. ${ }^{2} \mathrm{Dr}$ Gunjan Bhatia, MBBS, DCP Consultant Pathologist, GBH American Hospital, Udaipur, Rajasthan, India.

Address for correspondence:

Dr. Ravi Bhatia

Email: bhatiaravi.ped@gmail.com

\section{How to cite}

Bhatia R, Bhatia G. Haemophagocytic Syndrome in a Four Year Old Male Child with Plasmodium Vivax Infection. J Nepal Paediatr Soc 2016;36(2):193-195.

doi: http://dx.doi.org/10.3126/jnps.v36i2.15687

This work is licensed under a Creative Commons Attribution 3.0 License.

\section{(c) (i)}

\begin{abstract}
In Hyper endemic zones Malaria is known to present with unusual complications. Haemophagocytic syndrome is a disorder of mononuclear phagocytic syndrome. There are many published reports of haemophagocytic syndrome due to $P$. falciparum infection but haemophagocytic syndrome due to $P$. vivax infection is quite rare.
\end{abstract}

\section{Introduction}

$\mathrm{M}$ alaria is a major public health problem in India. In hyper endemic zones malaria is known to present with unusual complications. Haemophagocytic syndrome is a reactive disorder of the mononuclear phagocytic syndrome. There are many published reports of haemophagocytic syndrome associated with Plasmodium Falciparum infection but haemophagocytic syndrome due to Plasmodium Vivax infection is quite rare. We present a case of haemophagocytic syndrome in a four year old male child due to $P$. vivax infection.

\section{The Case}

A four year old male child was admitted to our hospital with complaints of high grade fever since seven days. Patient had two episodes of generalized tonic clonic convulsions on day of admission. Past medical and family history were unremarkable. On physical examination child was febrile, had pallor, hepato-splenomegaly, Glasgow Coma Score(GCS) score was 8 . The child was provisionally diagnosed as a case of cerebral malaria and was started on artesunate $2.4 \mathrm{mg}$ per $\mathrm{kg}$ body weight, followed by artesunate $1.2 \mathrm{mg}$ per $\mathrm{kg}$ after 12 hours on the first day, followed by artesunate for five days, intravenous phenytoin was given to control convulsions and packed RBC's were given to correct anemia. On admission the Complete blood count revealed a $\mathrm{Hb}$ of $4.2 \mathrm{gm} / \mathrm{dl}$, total leucocyte count of 2700 cells/cu mm with a differential count of polymorphs $37 \%$, lymphocytes $59 \%$, monocytes $02 \%$, eosinophils $02 \%$, platelet count was $56,000 /$ $\mathrm{cu} \mathrm{mm}$. The peripheral blood film was suggestive of microcytic hypochromic anaemia, thrombocytopenia with trophozoites and gametocytes of $P$. vivax. The parasite density was $6000 / \mathrm{cu} \mathrm{mm}$. The rapid diagnostic test (Optimal) was positive for $P$. vivax and negative for $P$. falciparum. CSF examination was normal. Blood culture was sterile. Peripheral blood film examination was done daily till complete parasite clearance was seen. Bone marrow examination was done in view of pancytopenia and it revealed erythroid hyperplasia with 
normal myeloid erythroid ratio, macrophages with haemophagocytosis and gametocyte forms of $P$. vivax were seen. On basis of bone marrow findings a diagnosis of haemophagocytosis secondary to $P$. vivax infection was made. Serum ferritin was $1000 \mathrm{ng} / \mathrm{ml}$ (reference range $15-330 \mathrm{ng} / \mathrm{ml}$ ), fasting triglycerides were $200 \mathrm{mg} /$ dl (reference range 40-180 mg/dl), and serum fibrinogen level was $0.8 \mathrm{gm} / \mathrm{l}$ (normal > $1.5 \mathrm{gm} / \mathrm{l}$ ). Urine analysis, Liver function tests, prothrombin time, activated partial thrombin time, G-6 PD levels, renal function tests, serum electrolytes were all normal. Tests for typhoid, dengue, hepatitis $\mathrm{B}$ and $\mathrm{C}, \mathrm{HIV}$ were all negative. $\mathrm{CBC}$ done after completion of antimalarial therapy revealed $\mathrm{Hb}$ of $6 \mathrm{gm} /$ $\mathrm{dl}$, total leucocyte count of $5600 \mathrm{cu} / \mathrm{mm}$ with a differential of polymorphs $50 \%$, lymphocytes $45 \%$, eosinophils $04 \%$, monocytes $01 \%$, platelet count was $78,000 \mathrm{cu} / \mathrm{mm}$. The peripheral smear was negative of malarial parasite. The child improved on anti-malarial treatment and was discharged on primaquine therapy for 14 days. Blood counts done one month later revealedHb of $9.2 \mathrm{gm} / \mathrm{dl}$, TLC $6700 \mathrm{cu} / \mathrm{mm}$, differential count of polymorphs 54\%, lymphocytes $45 \%$, eosinphils $01 \%$. The peripheral blood film was suggestive of microcytic hypochromic anemia. The patient was given haematinics and is doing well on follow up.

\section{Discussion}

Among the various complications of malaria, hematological complications of malaria are the commonest. Pancytopenia due to $P$. vivax infection is quite rare. Pancytopenia in malaria is a result of bone marrow suppression, micro angiopathic hemolytic anemia and rarely due to inappropriate macrophage activation secondary to haemophagocytic syndrome. Haemophagocytic syndrome is a distinct clinical entity which results from uncontrolled activation and proliferation of $T$ cells and macrophages ${ }^{1}$. It is characterized by pancytopenia, hyperferritenimia, hypertriglyceridemia and hypofibrinogenaemia. Till date this syndrome remains ill recognized in children often leading to delay in diagnosis. The usual causes of primary haemophagocytic syndrome are genetic, autoimmune diseases and malignancies. Secondary haemophagocytic syndrome has been associated with viral infections(Epstein barr virus, Cytomegalo virus, varicella), bacterial (gram negative organisms, pneumococcus, mycolpasma), fungal (Cryptococcus, candida albicans), parasitic (Babesiamicroti, Plasmodium falciparum, Strongyloides, Leishmania) $)^{1,2}$. Haemophagocytic syndrome due to $P$. vivax infection is very rare. The probable pathogenesis of haemophagocytic syndrome in $P$. vivax infection is due to inappropriate or excessive immunological response of $T$ cells. There is activation and elaboration of cytokines like IL-1, IL-2, IL-6 and TNF - alpha by T helper cells which promote activation of macrophages resulting in phagocytosis of the blood cells. These cytokines cause sequestration and rapid destruction of red blood cells. High levels of cytokines have been observed in cases of malaria which could well trigger haemophagocytic syndrome.

Our patient presented with fever, hepatosplenomegaly, pancytopenia, hyperferritenemia, hypertriglyceridemia, hypofibrinogenemia and haemophgocytosis in the bone marrow fulfilling the criterion laid down for diagnosis of HPS. Pothapregada et al have described haemophagocytic syndrome in a eight year old child with $P$. vivax malaria ${ }^{3}$. Tanwar et al have reported a case of hemophagocytic syndrome with $P$. vivax malaria ${ }^{4}$. Thapa et al have reported a case of pancytopenia in a seven year old girl child with cerebral malaria due to $P$. vivax infection ${ }^{5}$. Case reports of haemophagocytic syndrome due to $P$. vivax infection in adults have been reported more frequently,7.8,9,10.

\section{Conclusion}

Haemophagocytic syndrome should be suspected in all cases of malaria which present with pancytopenia and wherein the anemia does not improve even after appropriate anti-malarial therapy. Diagnostic bone marrow performed in cases of malaria which present with pancytopenia is useful in reaching a diagnosis of Haemophagocytic syndrome. 


\section{References}

1. Jabado N, Cusker C, Basille G. Pediatric Hemophagocytic syndromes: A Diagnostic and Therapeutic Challenge. Allergy Asthma Clinlmmunol2005;1(4):142-60 .

2. Albrech $H$, Schafer $H$, Stellbrink HJ, Greten $H$. Epstein-Barr virus-associated hemophagocytic syndrome. A cause of fever of unknown origin human immunodeficiency virus infection. Arch Pathol Lab Med 1997;121:853-8.

3. Pothapregada S, Kamlakanan B. Hemophagocytic syndrome in Plasmodium vivax malaria. JVector Borne Dis June 2014:51(2):144-46.

4. Tanwar G, Lahoti A, Tanwar P, Agrawal R, Khatri PC, Kochar DK. Hemophagocytic syndrome associated with severe plasmodium vivax malaria in a child in Bikaner. J VectorBorne Dis 2013:50(4):318-20.

5. Thapa R, Ranjan R, Patra VS, Chakrabarthy S. Childhood cerebral vivax malaria with pancytopenia. J PediatrHematolOncol 2009;31(2):116-17.
6. Park TS, Oh SH, Chi JC, Kim HH, Chang CL, Son HC. et.al. Plasmodium vivax malaria complicated by hemophagocytic syndrome in an immunocompetent serviceman. Am JHemato/2003;74:127-30.

7. Yamakawa $\mathrm{H}$, Kiyotakim $\mathrm{H}$, Hattari $\mathrm{Y}$, Obana $\mathrm{M}$, Matsuoka $Y$, Irimajiri S. A case of Plasmodium vivax malaria complicated with pancytopenia due to hypoplasia of the bone marrow. KansenshogauuZasshi1989;63(9):1043-46.

8. Pahwa R, Singh T, Khurana N. Hemophagocytic syndrome in malaria and kala azar. Indian J PatholMicrobio/2004;47(3):348-50.

9. Aouba A, Noguera ME, Caluvel JP, Quint L. Hemophagocytic syndrome associated with Plasmodium vivax infection. $\mathrm{Br} J$ Haemato/2000;103:832-33.

10. Ram Kumar TV, Baghmar S. Plasmodium vivax malaria complicated by neurological, jaundice and hemophagocytic syndrome. J Nepal PediatrSoc2010;30(3):168-70. 